\title{
Percepções e experiências do usuário no Parque Municipal de Belo Horizonte: estrutura, uso e manutenção
}

\section{Perceptions and user experiences in the Municipal Park of Belo Horizonte (MG, Brazil): structure, use and maintenance}

\author{
Ítalo Brener Carvalho, Marlusa de Sevilha Gosling
}

\begin{abstract}
RESUMO: Conhecer os valores experiência dos em áreas verdes de lazer urbano implica em uma análise do espaço geográfico onde esta prática se realiza. A observação das práticas urbanas da população se distingue no espaço-tempo (CERTEAU, 1994) no vivido e no percebido: conceitos apresentados por Lefebvre (1991). Com base na relação existente entre espaço-tempo e vivido-percebido, 30 coletas, por meio de observação participante, foram realizadas no Parque Municipal da cidade de Belo Horizonte. De forma exploratória o objetivo deste artigo é conhecer o cotidiano vivido e as experiências dos usuários neste espaço gratuito de lazer que podem ser observadas para o meio de relatos de percepção e da experiência vivenciada pelo visitante de um parque verde urbano. Os resultados confirmam (i) a contemporaneidade do pensamento da identidade no espaço (FOUCAULT, 1977), (ii) confirmam que as práticas espaciais influenciam as representações, (iii) a organização do espaço urbano (BOURDIEU, 1996) e (iv) as práticas urbanas no espaço e no tempo (BACHELARD, 1929). Este estudo contribui para evidenciar as avaliações positivas e ou negativas dos usuários perpassam por três parâmetros: Estrutura, Usos e Manutenção.
\end{abstract}

PALAVRAS-CHAVE: Espaço Público de Lazer; Percepções; Experiências; Estrutura; Uso; Manutenção.

\section{ABSTRACT}

In order to knowing the values experienced on green areas of urban leisure implies to analysis of the geographical-spatial since where this practice takes place. The observation of those population practices, it is distinguished in the space-time (Certeau, 1994); in the lived and the perceived: concepts presented by Lefebvre (1991). Based on the relationship between space-time and lived-perceived, 30 collections, through participant observation, were carried out in the Municipal Park of the city of Belo Horizonte. In an exploratory way, the objective of this article is to know the daily life and the experiences of the users in this free space of leisure. Observed to the means of reports of perception and the experience lived by the visitor of an urban green park. The results confirm (i) the contemporaneousness of identity thinking in space (Foucault, 1977), (ii) confirm that spatial practices influence representations, (iii) urban space organization (BOURDIEU, 1996) and (iv) urban practices in space and time (BACHELARD, 1929). This study contributions take place on how it can evidence the positive and negative evaluations of users measured by three parameters: Structure, Uses and Maintenance.

KEYWORDS: Public Leisure Space; Perceptions; Experiences; Structure; Use; Maintenance. 


\section{Introdução}

A temática do espaço urbano verde tem se mostra multidisciplinar e objeto de estudos, por exemplo, em ecoturismo, em turismo e em marketing turístico. Szeremeta e Zannin (2013) afirmam que estudos e pesquisas interdisciplinares com o envolvimento de especialistas de diferentes áreas de estudo poderiam contribuir para aumentar a percepção positiva, pela comunidade, de espaços públicos; efetivamente utilizados; possibilitando maiores níveis de atividade física e experiências psicológicas relevantes; para a melhoria da saúde.

Nos dias de hoje investigações interdisciplinares que promovam o avanço do conhecimento, do planejamento, da interpretação ou de educação relacionados ao lazer e bem-estar são consideradas relevantes. Segundo Rust e Huang (2014), Ostron et al., (2015) os potenciais benefícios gerados para a sociedade de pesquisas com propostas da melhorar o bem-estar dos cidadãos, são uma extensão lógica das funções de marketing.

É justamente as características multidisciplinares e interdisciplinares presentes na compreensão das vivências de usuários e de turistas de espaços públicos verdes urbanos que se permite não afirmar que uma resposta única, que um padrão formatado à um indivíduo idealizado que torna complexa a gestão e a satisfação dos visitantes.

Por esta razão a observação da organização social urbana contemporânea e da identidade com o espaço, são geralmente, observadas por meio das práticas urbanas muito mais abertas à criatividade e à coletividade (CERTEAU, 1994). Neste contexto, os parques urbanos ao oferecerem à seus usuários: acesso gratuito, um espaço livre de socialização, de liberdade, de promoção cultural ou educacional permitem que este fenômeno seja observado. Segundo Tuan $(1980,1983)$ os espaços da cidade são o lugar dos indivíduos, a cidade é um modo de viver, de pensar, de sentir, de produzir comportamentos, valores, conhecimento e obviamente lazer.

O desenvolvimento teórico-conceitual deste artigo tem a intenção de apontar nas práticas de lazer, influências para a (res) significação da experiência e a (re) configuração das percepções de espaços coletivos da cidade (GOMES; ELIZALDE, 2014). O que seriam reveladas, por exemplo, pelo cotidiano, pelo uso, por relações de identidade, encontro e sociabilidade observadas no campo pesquisado.

Como cada parque é único, um limitador desta pesquisa seria a dificuldade de se replicar integralmente, boas práticas observadas em um parque, em outros. Mas a compreensão das expectativas dos usuários e suas experiências poderiam, sim, serem investigadas inclusive, por suas diferenciações, como afirma Nadja et al., (2011). Desta maneira, certos parques oferecerem melhores serviços de convívio social, culturais ou educativos.

Segundo Lefebvre (1991) e Santos (2012) alguns lugares da cidade promovem o encontro e relações sociais, mas afirmam também a existência de uma crítica. O uso do emprego do espaço como uma mercadoria que é 
consumida diferenciando a possibilidade de que espaços públicos, na verdade, são tanto (i) um local de consumo, como (ii) objeto de consumo (LEFEBVRE, 1991). As pessoas além de consumirem os produtos ou serviços nesses lugares, consomem também o próprio lugar.

O mercado compreende o uso potencial de parques pelo turismo de forma padronizada, com uma reduzida preocupação com a satisfação dos diferentes públicos ou com real percepção da qualidade da experiência de seus visitantes nestes parques. Sendo, portanto, importante investigar melhor os interesses, preferências, valores, e opiniões diante de determinadas situações positivas ou negativas, (WEINSTEIN, 1995; BLAMEY; BRAITHWAITE, 1997).

As duas lacunas: o espaço-tempo e o vivido-percebido são direcionadas, neste estudo, pela teoria de Lefebvre (1991) que diferencia o acesso fenomenológico. Focando o comportamento do consumidor de espaço público verde em três dimensões da produção do espaço: o conceito de (i) "percebido" (perçu), de (ii) "concebido" (conçu) e de (iii) "vivido" (vécu). Essa tríade é, ao mesmo tempo, individual e social, e não é somente constitutiva da autoprodução do homem, mas da autoprodução de uma sociedade.

Assim o objetivo do presente artigo é investigar a experiência e a percepção dos usuários de um parque verde urbano em relação ao uso, estrutura e manutenção.

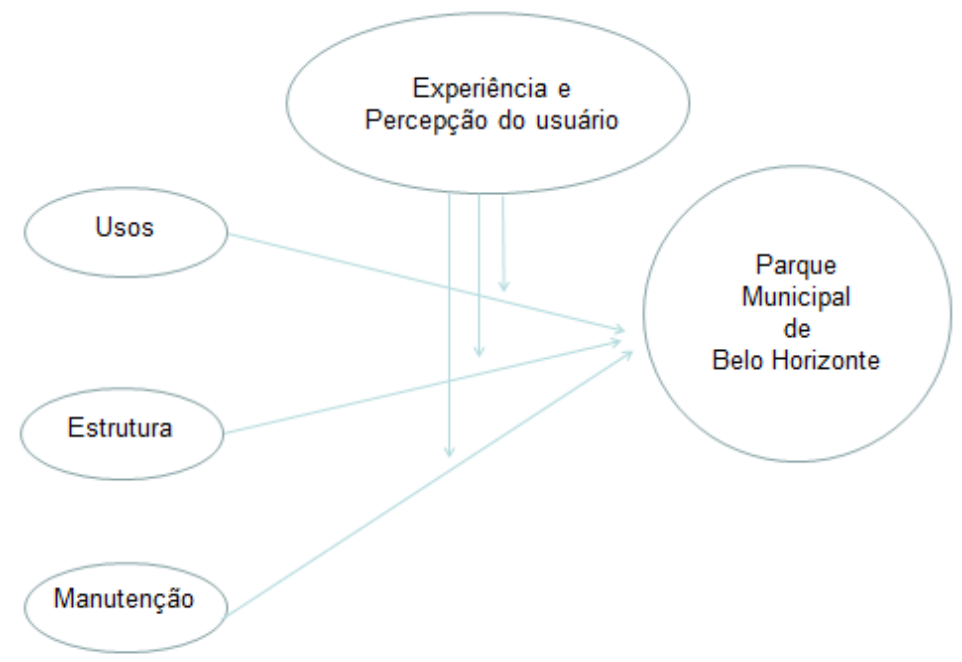

Figura 1: Modelo de pesquisa, sugerido por Cruz, Barbosa, Carvalho (2005) .

Fonte: adaptado pelos autores.

Figure 1: Research model, suggested by Cruz, Barbosa, Carvalho (2005) .

Source: adapted by the authors.

\section{Referencial teórico}

Diversos valores são associados à existência das áreas verdes naturais protegidas. São reconhecidos principalmente: o suporte à vida, valores econômicos, valores recreativos, valores científicos, valores estéticos, valores de biodiversidade, valores históricos, valores religiosos e filosóficos, simbolismo cultural e vida (LOCKWOOD, 2006). 
O que é evocado por um ambiente transforma um espaço em lugar, como por exemplo: nos sentimentos sobre este lugar, nas relações culturais e simbólicas de seus usuários. Este é o conceito de "sense of place" (WARF, 2006, p.234). Ou seja, os espaços urbanos (verdes ou não) podem ser motivadores de valores, de sentimentos, de reflexões e de experiências humanas e, portanto o cenário das interações sociais que os constroem, que reforçam ou transformam experiências cotidianas individuais ou para sociedade.

Os valores simbólicos de parques marcam e promovem uma cidade, atraindo, distintamente, dois tipos de visitantes: (1) a população local (MELO; DIAS, 2013) e (2) de turistas nacionais e internacionais (IRVING, et al., 2012). Estes locais contribuem para o debate sobre bem-estar, da preservação da natureza, de fomento ao lazer e a cultura não somente para ara população local, mas também expressam no imaginário da cultura local impressões nos turistas que ali chegam.

É um desafio a gestão de espaços públicos, como os parques municipais já que mantê-los conservados e atrativos, não é tarefa fácil. A presença das duas perspectivas coexistentes no mesmo espaço: a primeira de promover o lazer para os moradores e locais (GOMES; ELIZALDE, 2014), e a segunda, a perspectiva do turista visitante, que durante um tempo livre visitam estes espaços (IRVING, et al., 2012).

\section{Os parques verdes urbanos}

Os Parques Urbanos são espaços verdes localizados em áreas urbanizadas de uso público, propiciar recreação e lazer aos usuários e em sua maioria, oferecem serviços culturais já que alguns possuem casas de espetáculo ou centros culturais e educativos (TOLEDO; SANTOS, 2008).

Normalmente ligados a atividades em áreas abertas e livres, representam o lazer da cidade, capazes de estabelecer relações sociais, por meio das atividades esportivas, culturais, educativas, artísticas, ambientais e contemplativas (IRVING, et al., 2012).

Neles a população urbana desenvolve uma relação com a natureza, o que faz dos parques um importante equipamento urbano, promovendo a proteção da biodiversidade e dos recursos naturais remanescentes áreas urbanas e considerado como uma importante alternativa para recreação de moradores dos bairros localizados em seu entorno (PELLIN; CARVALHO; REIS, 2014). Propiciando os laços sociais, contribui para a coletividade e também promove o bem viver pelas práticas experienciais nestes locais. É, portanto um equipamento de conscientização ambiental que estimula valores associados à integração.

E mais, além disso, estes equipamentos de lazer promovem uma ligação com as práticas de turismo, educação e atividades que visam à aproximação de visitantes, com a população e a vida local com um ambiente natural (BENCKENDORFF et al., 2009; MOSCARDO, 2009; STREGLIO; OLIVEIRA; 2011). Porém, infelizmente, o acesso a esses benefícios não é vivenciado e percebido por todos. 


\section{Lugar e hora para tudo: o espaço em análise}

As relações dialéticas entre homem e lugar, em que esse último seria uma construção humana. Visto que objeto (espaço-ambiente), conduziriam as ações humanas quer variam de acordo com a experiência com o ambiente em seus muitos matizes (TUAN, 1980, 1983). Mesmo que um espaço seja planejado, concebido para uma função social, muitas vezes, não atinge plenamente seus usuários.

É que os espaços carregam consigo um simbolismo explícito de representações da produção do cotidiano, do particular, do vivido. De mensagens transmitidas pelas representações de relações sociais e percepções (Lefebvre, 1991). Assim, duas categorias definiriam o espaço e seu uso no cotidiano: (1) o tempo (hora) e (2) o espaço (lugar). Segundo Santos (1982), estas duas categorias justificam a cristalização dos espaços pelo tempo, mediante a identificação e a constatação de uma ordem segundo a qual os sujeitos se organizam o sistema temporal e espacial, formando um novo sistema temporal/espacial entre os dois.

Para compreender melhor essas categorias e a renovação tempo/espaço, Lefebvre (1991) e Harvey (2005) destacariam a significação da transformação do espaço pelo tempo, ou, do tempo pelo espaço. Lefebvre (1991), o primeiro autor que este estudo utiliza, contribui com as dimensões (1) do vivido, (2) do percebido e (2) do imaginado. A primeira dimensão se refere aos processos de interação, a segunda, às representações do espaço e a terceira, por fim, diz respeito à utopia, à abertura para futuro, às projeções, à imaginação.

Já a contribuição do segundo autor, Harvey (2005) acrescenta a este estudo a dicotomia entre o tempo e o espaço e sua representação, respectivamente usando o tempo como uma categoria da vida humana em metamorfose (deslocamento e velocidade) ou na atemporalidade capaz de identificar valores permanentes, essenciais ou eternos.

Os dois autores, Lefebvre e Harvey são constantemente citados em estudos similares a este, por refletirem sobre transformação e dinamicidade dos espaços. Segundo Tuan $(1980,1983)$ a relação do espaço com o tempo coaduna com as matizes cultural, social, no contexto histórico da industrialização massificada, compreendendo o momento em que o urbano se torna objeto estudo.

Harvey (2005) e Lefebvre (1991) ao tratarem da experiência do tempo e do espaço, descrevem a modernidade como uma fase de dissolução, baseada na coletividade e na espacialidade, propondo que o percebido, 0 concebido e o vivido se convergem para (re) produção do espaço.

Contextualizando para tornar mais fácil uma exemplificação das variáveis tempo que é influenciando o espaço seria o período de férias. Segundo Nawijn e Veenhoven (2011) um efeito estatístico relevante impulsiona felicidade, a busca pelo bem-estar individual ou de famílias, impactaria tanto a visitação como na escala de satisfação com espaços de lazer. Ou seja, o período de férias estimula a vista, mas também níveis mais altos de satisfação com serviços consumidos neste período. 
Evidencia-se assim que os fenômenos espaciais/temporais simultaneamente corroborar para o planejamento do concebido, nas experiências vividas e no percebido no cotidiano dos usuários, discussão que será desenvolvida a seguir.

\section{O planejamento do concebido, as experiências do vivido e o percebido pelos usuários}

Corroborando com os autores até aqui supracitados, as obras de Bachelard (1993) e de Foucault (1975) também inserem em suas discussões o pensamento do espaço/tempo e do concebido/vivido/percebido, na verdade, a fusão espaço-tempo segundo estes autores demostram como tudo está contra a proposição da ideia de que: "só vivemos o tempo esquecendo o espaço, só entendemos o espaço suspendendo o curso do tempo" (BACHELARD, 1929, p. 99) e de que "o tempo penetra no corpo, e com ele todos os controles minuciosos do poder" (FOUCAULT, 1977, p.129).

Por isso, a compreensão da problemática do espaço implica em relacionar criticamente 0 vivido, o percebido e o concebido. Considerada uma crítica, afirmando que a prática social, modifica, transforma os espaços. Mas como não existe tal crítica, o usuário do espaço, o turista ou morador tendem a fazer abstrações de sua própria prática com e no espaço.

Em tese o indivíduo corroboraria na produção do espaço. Segundo Santos (1999) e Gomes e Elizalde (2014) a produção do espaço por um indivíduo, acontece a partir do significado, em função do lazer, produzido coletivamente, mas que é apropriado individualmente.

Nesse sentido, o espaço verde urbano em análise é construído e constituído pelo homem. Não se congela no tempo, se transforma e se modifica em função do tempo e dos lugares que vivência. Vivências que acontecem em ambientes naturais preservados pelo parque, a exemplo de acesso a características históricas e culturais da cidade, contribuem para percepção do visitante, sentindo-se como se fizesse parte desta realidade (MAFRA, 2010).

É complexa a ideia de viver bem no espaço urbano. Afinal esta relação varia de acordo com cada cultura, varia entre os indivíduos e entre o coletivo. Segundo Tuan (1983) o bem viver é a própria experiência de viver (bem-estar), não se reduz apenas a uma experiência individual, apresentando a ideia de uma construção em conjunto, em sociedade e pelo acumulo de experiências individuais, resultando em escolhas e comportamentos específicos.

Observar e analisar as práticas dos usuários, no contexto do uso (MALTA; COSTA 2009), seu envolvimento e o grau de interação com que o espaço urbano, deixa de ser somente objeto de conhecimento, mas, principalmente e, sobretudo um lugar de reconhecimento (CERTEAU, 1984) de si mesmo, de atributos e de valores. 


\section{Valores e atributos associados à existência de áreas urbanas: valores estéticos, socioeconômicos, culturais e educacionais}

A diversidade de valores e atributos é o que permite organizar uma série de reflexões, acerca do desempenho, desses espaços na dinâmica local (STREGLIO; OLIVERIA, 2011). Alguns valores relacionam parques verdes com conscientização ambiental, sociabilidade e bem-estar do indivíduo ou então, como equipamentos que promovem o bem viver social (PELLIN, et al., 2014; MELO; DIAS 2013; IRVING et al., 2012).

Valores e atributos do uso de parques públicos (FEIBER, 2004) são evidenciados quando um visitante relata que são motivados a visitar estes espaços pelas atrações naturais e estéticas de parques. Segundo Baloglu e Uysal (1996) motivações relacionadas à aprendizagem de coisas novas, a vivência de experiências diferentes.

Dessa forma um lugar não é apenas um espaço físico, mas também uma localização significativa, interpretada, narrada, entendida e sentida, que depende das práticas espaciais e das representações e a organização do espaço urbano (BOURDIEU, 1996). Um exemplo disso seria a importância e a representação histórica de alguns parques, como os antigos parques europeus que proporcionam com diferentes significados e perspectivas da cultura de um lugar.

Segundo Lefebvre (1991) e Santos (2012) alguns lugares da cidade promovem o encontro, relações sociais onde os indivíduos usufruem do espaço considerando esse como mercadoria. Isso significa que espaços públicos, na verdade, são tanto um local de consumo, como objeto de consumo (LEFEBVRE, 1991). As pessoas além de consumirem os produtos ou serviços nestes lugares, consomem também o próprio lugar. O Quadro 1 a seguir, resume bem as categorias observadas.

Quadro 1: Alguns valores e benefícios associados à existência de áreas protegidas urbanas.

Table 1: Some values and benefits associated with the existence of urban protected areas.

\section{Ambientais}

Proteção de uma amostra do ecossistema e da biodiversidade

Aumento da permeabilidade do solo em meio urbano

Controle da poluição atmosférica e sonora

Regulação microclimática

\section{Socioeconômicas e Culturais}

Possibilidade de melhoria na qualidade de vida de usuários

Prover espaço de interação social

Oportunidade de recreação em contato com a natureza para moradores do entorno e usuários

Diminuição do stress da vida urbana

Conservação de patrimônio histórico-cultural

Proteção de belezas naturais

Descontinuidade da malha urbana

Diminuição da poluição visual

Estéticos

Continua.. 
Educacionais ou de Sensibilização

Ambiental (formal ou ensino informal)

Integração entre pessoas do entorno

Interação de visitantes devido ao seu fácil acesso

Interação com usuários ocasionais que utilizam a área apenas para passagem ou para realização de atividades esportivas ou recreativas

Sensibilização quanto à importância da conservação dessas e de outras áreas naturais

Fonte: adaptado pelos autores a partir de Menezes; Mendes (2001); Melazo; Colasanti

(2003); Gomes; Soares (2003); Souza (2010); Pitt; Boulle (2010); Brigs (2012).

Source: adapted by the authors from Menezes; Mendes (2001); Melazo; Colasanti (2003);

Gomes; Soares (2003); Souza (2010); Pitt; Boulle (2010); Brigs (2012).

Os valores e os benefícios relatados no Quadro 1 denotam, ao mesmo tempo e no mesmo espaço, processos ativos individuais e sociais. Por isso a necessidade de investigação de campo, para que sejam investigados: (1) o uso do espaço urbano e seus equipamentos de lazer; (2) a apropriação desses lugares criando identidades; (3) a democratização do lazer e o papel das políticas públicas; (4) a política de reordenação do solo urbano e (5) políticas de formação e desenvolvimento de pessoal e corpo técnico eficiente e atualizado.

\section{Métodos}

Conforme sugere Malhotra (2012) esta pesquisa pode-se classificada quanto a sua finalidade como exploratória, pois é constituída por meio de levantamentos bibliográficos em uma perspectiva teórica. Possui uma abordagem predominantemente qualitativa. Possui 30 roteiros de entrevistas realizados de forma não probabilística e aleatória, coletadas em duas visitas a campo no Parque Municipal da cidade de Belo Horizonte, Minas Gerais.

A interpretação dos dados se deu pelo método análise de conteúdo (BARDIN, 2009), respaldada pelas observações in loco. Quanto aos meios a pesquisa se caracteriza como uma observação participante (CRESWELL, 2010), embasada por entrevistas semiestruturadas. Buscou-se capturar as sensações, valores e significados através de perguntas abertas que avaliam a percepção do parque e dos sentimentos do visitante naquele momento. Segundo Creswell (2010), esta técnica: (1) facilita o acesso rápido em situações habituais em que os membros de uma comunidade se encontram envolvidos; (2) facilita que o pesquisador tenha a liberdade de mudar o foco das observações ou concentrar em fatos inesperados, e a comparação entre as informações recebidas das pessoas pesquisadas e a própria realidade. Por outro lado, (3) o cuidado com que percepções próprias e impressões sensoriais, já que erroneamente, vez por outra, pode-se conduzir o pesquisador a tirar conclusões precipitadas (COOPER; SCHINDLER, 2003).

Essa técnica auxilia o pesquisador a obter e identificar premissas sobre os objetivos que os indivíduos não têm consciência ou que guiam seu comportamento e desempenha papel importante, pois obriga o investigador a estabelecer um contato direto com a realidade estudada (COOPER; SCHINDLER, 2003). 
A observação foi realizada em duas visitas, o pesquisador circulava livremente pelas áreas do parque, observava os relacionamentos e as interações que aconteciam, interagia com os visitantes e socializava.

Esta metodologia foi aplicada por Cruz, Barbosa, Carvalho (2005), e é composta por duas etapas: 1. Observação e registo no local de três parâmetros: Estrutura, Usos e Manutenção; 2. Apreciação geral: recolhendo opiniões e sugestões referentes à: (1) Estrutura estética, recursos disponibilizado, equipamentos e aparelhagem de lazer. (2) Usos, Faixas etárias, Classes socioeconómicas, Atividades indesejadas (criminalidade, delinquência, drogas, moradores rua, etc.). (3) Manutenção, Opiniões e sugestões detalhadas obtidas junto aos utilizadores (Quadro 2).

Quadro 2: Resumo metodologia e interseção teórica sugerido por Cruz, Barbosa, Carvalho (2005).

Table 2: Summary methodology and theoretical intersection, suggested by Cruz, Barbosa, Carvalho (2005).

\begin{tabular}{cccc}
\hline Metodologia & $\begin{array}{c}\text { Critérios } \\
\text { qualitativos }\end{array}$ & $\begin{array}{c}\text { Relevância } \\
\text { aplicabilidade }\end{array}$ & Objetivo \\
\hline $\begin{array}{c}\text { 1. Observação/registro } \\
\text { no local dos parâmetros }\end{array}$ & $\begin{array}{c}\text { Estrutura } \\
\text { Usos } \\
\text { Manutenção }\end{array}$ & $\begin{array}{c}\text { Base de levantamento } \\
\text { exploratório }\end{array}$ & $\begin{array}{c}\text { Conhecer as práticas } \\
\text { percebidas e vivenciadas } \\
\text { no parque municipal de } \\
\text { Belo Horizonte }\end{array}$ \\
\hline 2. Apreciação geral & $\begin{array}{c}\text { Opiniões e } \\
\text { sugestões }\end{array}$ & $\begin{array}{c}\text { Base de levantamento } \\
\text { exploratónio a } \\
\text { sentimentos, } \\
\text { experiências e avaliação }\end{array}$ & \\
\hline
\end{tabular}

Fonte: adaptado pelos autores.

Source: adapted by the authors.

Neste estudo, foram observados os elementos constitutivos referentes a sentimentos, experiências, a interação e satisfação com o espaço físico. Após a coleta de dado, empreendeu-se a técnica de análise de conteúdo, a fim de analisá-los e propor discussões com base na técnica, sendo descrita na próxima sessão.

\section{Resultado e discussões}

Constata-se no Quadro 3 a frequência de visitação de pessoas de vários grupos etários, mas caracterizado principalmente por adolescentes e idosos, e a presença de grupos como os esportistas e os moradores de rua (ressalta-se que o número de moradores de rua no espaço é cada vez maior) e até a constatação do consumo de drogas.

Nesse contexto, os autores Gomes e Elizalde (2014) confirmam que a necessidade de lazer pode ser satisfeita de múltiplas formas, segundo os valores, crenças e interesses dos sujeitos, grupos e instituições em cada contexto histórico, social e cultural. 
Quadro 3: Frequência de usuários do Parque Municipal de Belo Horizonte.

Table 3: Frequency of users of the Municipal Park of Belo Horizonte.

$76 \%$ dos entrevistados relata não ser a primeira vista ao parque

$12 \%$ se declara frequente

$16 \%$ declara ser a primeira vista e desse percentual, 4 respondentes não moram na cidade

Fonte: Dados da coleta.
Source: Data collection.

Sobre a escolha do parque, da motivação e o interesse quanto ao parque, observa-se nos relatos a importância (1) do acesso livre e gratuito da população, esta área verde de domínio público exceto as segundas feiras dia de organização e (2) acesso garantido, central facilita a frequência pelos visitantes, ressaltando essa como uma das principais características do parque urbano central, sua gratuidade e acessibilidade.

Quadro 4: Em sua opinião por que as pessoas vistam o parque?

Table 4: In your opinion why people see the park?

\begin{tabular}{l}
\hline \multicolumn{1}{c}{ Interesse } \\
\hline "é uma opção de passeio gratuito legal, tem bichos, e é bem central." \\
"ser gratuito ajuda a trazer mais pessoas, mesmo sem dinheiro se diverte, elas querem \\
lazer." \\
"aqui é fácil de vir, é gratuito e sempre tem umas atividades legais pra criança."
\end{tabular}

Fonte: Dados da coleta.

Source: Data collection.

Tanto a frequência como os interesses e a motivação, refere-se constantemente a atividades sociais e ou recreativas. O parque é utilizado por diferentes motivações, durante a semana ou finais de semana. Os usuários entrevistados relatam interesses na contemplação estética e da natureza, a manutenção da saúde, abstração da realidade da rua, a busca pelo equilíbrio e harmonia como os principais fatores motivadores para a frequência no lugar.

Quadro 5: Categorias que justificam a motivação de vista ao parque.

Table 5: Categories that justify the park view motivation. Collection data.

Contemplação estética e da natureza

Motivadores

Manutenção da saúde

Abstração da realidade

Equilíbrio e harmonia

Fonte: Dados da coleta.

Source: Data collection.

Isso sugere que, independentemente da relação do visitante com o parque, sendo este morador ou de outra cidade, da formação ou idade, a percepção dos benefícios do parque para a cidade e do parque para com os visitantes é latente.

Os entrevistados apontam que o parque pode representar uma experiência que melhora a qualidade de vida dos visitantes. Afirmativas que destacam esta percepção relatam que usuários quando está experienciando 
a vista, teriam o sentimento de relaxamento, de felicidade, de alegria (LAGE, MILONE, 2000).

Quadro 6: Sentimentos evocados durante a vista a este parque. Fonte: Dados da coleta.

Table 6: Feelings evoked during the view to this park. Source: Data collection.

Sentimentos

Fonte: Dados da coleta.

Source: Data collection.

Duas observações merecem destaque: (1) a repetição do sentimento de relaxamento, calma e bem-estar; (2) e a percepção do espaço de conversa ou do espaço do silêncio em que ambas referem ao alivio do estresse. Percebe-se como o parque é um espaço de socialização, de vivência e de compartilhamento. Relacionado com suas funções sociais.

No entanto, o uso destas áreas depende de vários fatores sociais e ambientais presentes no ambiente destas áreas e características individuais dos seus usuários como, por exemplo, idade, condições socioeconômicas, gênero, escolaridade (SZEREMETA; ZANNIN, 2013). Quando perguntados sobre o que justificaria o não uso do parque alguns entrevistados relataram a percepção é que (1) é inseguro, (2) falta de tempo (3) custo de deslocamento (4) desinformação, do que acontece no parque e de que o equipamento seria destinado a classes sociais baixas.

Quadro 7: Porque as pessoas não vistam este parque? Fonte: Dados da coleta.

Table 7: Why do not people see this park? Source: Data collection.

\section{Não uso e frequência ao parque}

"tem gente que acha que é divertimento de pobre ou acha que é perigoso."

"tem gente que passa aqui na porta e nunca entrou, podem achar perigoso."

"falta de tempo"

"algumas pessoas acham que lazer, cultura não são importantes pra elas."

"talvez porque não tem dinheiro para vir, e nem é caro ne... é até de graça... se não quiser gastar nada não gasta."

"se soubessem que não é só área verde tem shows, teatros e concertos poderiam vir mais."

Fonte: Dados da coleta.

Source: Data collection.

As expectativas de um público essencialmente urbano em contato uma área verde precisam ser monitoradas para que se reconheçam fatores considerados de "evitação" (BALOGLU; UYSAL, 1996) e as expectativas de não-usuários.

Os visitantes de parque públicos podem ser segmentados buscando um enquadramento de consumidores, segundo Weinstein (1995) e Blamey; Braithwaite (1997) uma segmentação pode propor organizar a demanda a partir de divisões do perfil dos consumidores permitindo-se que, por exemplo: se reconheça o fluxo turístico do local observado.

Uma segmentação psicográfica e comportamental permite estabelecer padrões de atitude para os diferentes grupos de visitantes, a 
segmentação comportamental diz respeito aos hábitos do público, aos costumes de determinado grupo ou família que visita uma área verde.

Uma segmentação objetiva conhecer melhor as motivações dos visitantes, suas reações diante de determinadas situações positivas ou negativas, revelando ainda motivações, interesses em atividades, preferências, atitudes, valores, opiniões e estilos de vida (WEINSTEIN, 1995; BLAMEY; BRAITHWAITE, 1997).

Porém quanto às respostas direcionadas para o uso do parque (FEIBER, 2004) os dados foram inconclusivos, respostas distintas não permitiram dizer que as pessoas usufruem ou gostam. Mas algumas entrevistas mesmo que pontuais relatam atividades simples, como atividades importantes para usuários: sentar de baixo de uma árvore, ler, refrescar, passear, ir aos brinquedos, usar os brinquedos, dar uma pausa, buscar o silencio ou simplesmente a contemplação da natureza.

Observou-se que o espaço é considerado uma referência local, um ponto de livre acesso que congrega "várias tribos" que se encontram dividindo e por vezes compartilhando o mesmo espaço.

Durante as entrevistas a importância dada ao espaço é claramente evidenciada pelas falas dos entrevistados. De que um parque preserva a natureza e um espaço de lazer. Há relatos onde se considera os parques como a beleza natural próximo de casa, como possibilidade de local de integração. Mas características relacionadas a educação e aprendizado (COSTA; COSTA, 2011) entre pais e filhos, envolvidos nas brincadeiras que um local proporciona é destacada.

Quadro 8: Alguns valores e benefícios associados à existência de áreas protegidas urbanas.

Table 8: Some values and benefits associated with the existence of urban protected areas. Valores educacionais e de sensibilização relacionados à

Cuidados com a saúde

Cidadania e valorização do espaço público

Meio ambiente

Convívio social

Fonte: Dados da coleta.

Source: Data collection.

Benckendorff et al., (2009) e Moscardo (2009) relatam que um dos valores de espaços públicos similares ao estudado, é a conservação por meio da educação, da qualidade de vida, valores estéticos e de bem-estar encontram apoio na educação ambiental para visitantes e comunidade local, estimulando o desenvolvimento do nível educacional da comunidade local. E o desenvolvimento relacionado entre espaço e cidadania (MELO; DIAS, 2013).

Pode-se dizer que o parque promove a educação do indivíduo (COSTA; COSTA, 2011), o espaço e a experiência vivenciada no parque poderiam então um (re) ordenar o pensamento, conscientizar usuários, valorizando o espaço, mas também o tempo, o tempo do relaxamento, o 
tempo da contemplação, o espaço do lazer, o espaço da recreação e do convívio social.

De acordo com Melo e Silva (2013), a identidade confere a um povo o sentimento de coletividade e pertencimento ao grupo e o diferencia dos demais. Sendo formados através de um processo de legitimação social e cultural de objetos e costumes, símbolos que transmitem a cultura através das gerações e possibilitam a manutenção de um vínculo com o passado.

O sentido simbólico, o sentido da representação, do que o parque representa estava presente em duas perguntas, e delas algumas evidências podem ser apontadas.

Quadro 9: O que o parque representa? Fonte: Dados da coleta.

Table 9: What does the park represent? Source: Data collection.

\section{Representação e simbólico}

"o parque representa uma praça grande no centro da cidade só que com árvores."

"é um marco central da cidade, todo mundo conhece, é um ponto de localização, representa a cultura a mineiridade local."

"representa ser mineiro e o jeito devagar de ver e viver a vida."

"o parque municipal de Belo Horizonte é uma joia verde que se destaca na vida da cidade, ajuda a melhorar a vida das pessoas como um local de descanso."

"sim, acho que é turístico conhecer os principais pontos da cidade e aqui é um ne."

"quem quer vir a bh tem de conhecer o parque municipal e o mercado central e a feira hippie né."

\section{Fonte: Dados da coleta.}

Source: Data collection.

Sendo assim considerado como uma referência histórica, de lazer e que representa parte da cultura da cidade, mas também é uma representação da memória afetiva da cidade. Segundo Irving, et al., 2012) estes locais quando contribuem para o debate sobre bem-estar, natureza e cultura expressam o imaginário da cultura local, das práticas espaciais que influenciam as representações e a organização do espaço urbano (BOURDIEU, 1996) e geram impressões nos turistas que ali chegam.

Destaca-se a contribuição das falas que relatam que 0 parque municipal é considerado um marco, um elemento importante que constitui a cidade, e está intimamente relacionado com outros atratores próximos como o mercado central e a feira-hippie.

Por fim, o último questionamento que pôde ser destacado é a infraestrutura do parque. E quais sugestões e opiniões os usuários fazem na avaliação da infraestrutura do parque. Em sua maioria satisfatória por parte dos usuários relatam. 
Quadro 10: Criticas comentários e sugestões para a gestão do parque.

Table 10: Critical comments and suggestions for park management.

\footnotetext{
"tem pouco banheiro."

"aqui é bom, mas acho perigoso, às vezes."

"podia ter mais eventos já vi cantores, orquestra e teatro isso é muito bom, as pessoas viram mais se tivesse mais eventos."

"ter lugar de beber agua ou lanchonete acho que só tem uma e os carrinhos de picolé espalhados."

"criar espaços onde as pessoas podem disfrutar de um espaço que não se encontra em outros ambientes da cidade, algo mais diferente."

"como os parques também têm grande importância ecológica podiam estimular os jovens estudantes a frequentar mais aqui."

"áreas de eventos musicais, companhas de saúde e esporte, possui um teatro para eventos teatrais, faz parte chamar as pessoas pra isso né."
}

Sugestões

Fonte: Dados da coleta.

Source: Data collection.

Apesar da maior parte dos usuários relatarem que estão satisfeitos com os equipamentos disponibilizados e que a estrutura é adequada. Existe uma relação teórica entre a recomendação e satisfação. No questionamento sobre a recomendação a outros usuários sobre a experiência vivenciada do visitante, quase a totalidade dos entrevistados relata que sim, recomendaria a vista a outras pessoas.

Mas também relatam que alguns itens da prestação do serviço poderiam merecer um maior cuidado da administração do parque. Os entrevistados apontam sugestões identificadas e percebem a necessidade de haver pouco mais de segurança no local ou da necessidade dos próprios frequentadores mudarem o comportamento em prol da conservação do espaço.

Estes itens merecem, portanto, serem pesquisados com mais cautela e em uma amostra maior: (1) à limpeza de banheiros; (2) segurança, uma categoria que segundo os entrevistados refletem 0 entendimento de estrutura, surpreendentemente, é que entrevistados dizem que os frequentadores precisam ser mais educados e cuidar do lugar.

Considerado um local propício para atividades de lazer e referencia exuberante de área verde dentro da cidade, evidencia-se a existência de uma percepção maior acerca do bem-estar, do sentimento de prazer, experiências de lazer únicas. Os entrevistados reconhecem que o parque representa uma área verde de domínio público e que suas funções paisagística e recreativa, qualidade estética, funcional e ambiental para a cidade.

É evidente que as funções ecológica, paisagística e recreativa, propiciando a melhoria da qualidade estética, funcional e ambiental, mencionada no concebido da normativa não é completamente percebido ou vivido pelos visitantes. Os dados empíricos apontam que o consumidor é ciente das transformações propostas pela inclusão social e urbana de espaços de livre lazer, especificamente de parques que podem atuar como catalizadores da saúde e bem-estar. 


\section{Conclusões}

As categorias apresentadas neste estudo corroboram para analise de pesquisas que relacionam os lugares como objeto de consumo. Os temas apresentados confirmam as teorias da transformação urbana dos espaços públicos e a experiência de consumo construída por seus usuários.

Ao compreender que o espaço urbano de lazer pode ser analisado pelas óticas de Lefebvre "o concebido, o percebido e o vivido" e também de como as oportunidades no cotidiano das pessoas em relação ao tempo e espaço se diferem. Ou seja, umas com mais outra com menos, o tempo para práticas de lazer não é igual para todos quando analisado pelas duas categorias: a disponibilidade do espaço e a disponibilidade de tempo.

As análises e interpretações dos dados coletados as relações da fusão entre a cidade e seus espaços, com as práticas urbanas e os comportamentos sociais de Certeau (1994). O que possibilita concluir que as práticas temporais e espaciais influenciam as representações e demandam organização do espaço urbano de lazer.

Sintetizando o objetivo deste trabalho que foi: investigar a experiência e a percepção dos usuários de um parque verde urbano em relação ao uso, estrutura e manutenção, os relatos dos entrevistados sintetizam:

a) Referentes à "Estrutura" se concentraram em afirmar que em geral (estilo, beleza, programação, arborização ou vegetação) são considerados adequados. $O$ espaço aberto, com sombra e frescor estimula a passagem e a permanência de usuários, que descrevem a intenção da prática de lazer, descanso, esporte ou apenas de um passeio. É possível dizer que os equipamentos de lazer, de prática esportiva e de apoio ao usuário são bem avaliados, apesar de ser observada a necessidade de lanchonetes, quiosques, lixeiras e banheiros.

b) $\mathrm{Na}$ análise do parâmetro relativo aos "Usos", por meio da observação no local requer por parte dos gestores públicos atenção especial. A conclusão é de que as atividades (lazer, passeio, esportes, descanso) são fortemente relatadas, mas também os eventos (feiras, festas, comemorações) são considerados como "uso efetivo dos espaços de lazer", sendo de fundamental importância para a análise e compreensão das necessidades da população, adaptação do espaço e sugestão de investimento.

c) No parâmetro da "Manutenção", foi considerada positiva e bem avaliada. A qualidade da manutenção, a conservação do patrimônio considera o parque, limpo, organizado e adequado. Porém há relatos quanto à necessidade de maior sensação de segurança, e este item é incluído nesse fator de avaliação, é uma necessidade diária e que requer evidenciala.

d) O último parâmetro analisado, ao se recolher opiniões e sugestões, uma subjetividade de uma "apreciação geral" dos utilizadores é apontada por este estudo: ao se padronizar os comportamentos massificados e o uso do espaço público, as relações com o espaço estariam congeladas o que poderia configurar segregação socioespacial. 
Ressalta-se que o componente estético como estátuas, monumentos, coretos, teatro aberto, e obras de arte não foram apontados nas opiniões, mas o observador registra que existem estas estruturas. $O$ destaque nas opiniões coletadas com o usuário reforça o elemento natural, a arborização, o verde. E que é fundamental como já afirmava Carlos $(1994,1999)$ exemplos desse congelamento massificado do comportamento e do uso dos espaços desaparecem, as funções do lugar mudam: a rua passa a ser apenas um lugar da passagem. Evitar a perda da memória do lugar, o estranhamento do novo, a não identificação, o não pertencer, não se relacionando com o lugar e a não frequência e uso.

Concluímos que a seguinte proposição pode ser apresentada: (1) o espaço de lazer é uma realidade prática, constituída ao longo do tempo. Sendo considerada tanto como meio e como produto social. Entender o espaço como lugar que é consumido e que seu consumidor alterna as variáveis que influenciam e motivam seu consumo, apropriação e avaliação.

Esta discussão permite que novas sugestões propositivas à criação de espaços inteligentes, de centros deslocados para jovens, para idosos, para o esporte, reunindo em um só espaço, lazer e entretenimento que atendam a novas necessidades e aos novos comportamentos de apropriação do local.

Este estudo possui limitações, inclusive de tempo e orçamento, a obtenção de dados mais rigorosos requer a intensa observação do espaço, sendo considerado um limitador desta pesquisa. E com a intenção de não generalizar a ocupação/utilização do espaço de lazer em função apenas do horário escolhido para a pesquisa de campo. Como esta pesquisa foi realizada em período diurno, em apenas dois dias, recomenda-se a busca em períodos alternativos e espaçados.

Sugerir estudos futuros que incorporem as questões de lugar como objeto de consumo e das relações entre consumo de espaço e bem-estar, é considerado uma extensão promissora. O consumo de espaço através do lazer e do turismo, espaços naturais transformados em mercadorias, característica que talvez sejam inerentes a um homem moderno. Como muitas vezes não existe crítica às práticas sociais que modificam e transformam os espaços, consequentemente não há identidade com 0 espaço, como também não há influencia das práticas espaciais nas representações e na organização do espaço urbano.

\section{Referências}

BACHELARD, G. La valeur inductive de la relativité. Paris, Vrin. 1929.

BALOGLU, S.; Uysal, M. Market segments of push and pull motivations: a canonical correlation approach. International Journal of Contemporary Hospitality Management, v. 3 (8): 32-38. 1996. 
SZEREMETABANI, B.; ZANNIN, P.H.T. A Importância dos Parques Urbanos e Áreas Verdes na Promoção da Qualidade de Vida em Cidades. Raega - 0 Espaço Geográfico em Análise Curitiba, v.29, p.177-193. 2013.

BARDIN, L. Análise de Conteúdo. Edições 70, LDA, Lisboa, Portugal. 2009. BENCKENDORFF, P.; EDWARDS, D.; JUROWSKI, C.; LIBURD, J.J.; MILLER, G.; MOSCARDO, G. Exploring the future of tourism and quality of life. Tourism and Hospitality Research, 9(2), 171-183. 2009.

BLAMEY, R. K.; BRAITHWAITE, V.A. A social values segmentation of the potential ecotourism market. Journal of Sustainable Tourism, v. 5, p. 2945. 1997.

BOURDIEU, P. Espaço social e espaço simbólico. In: BOURDIEU, P. Razões práticas. Sobre a teoria da ação. Campinas, SP. Papirus. 1996.

CARLOS, A.F.A. Pensando novos caminhos da geografia urbana. Anais do II Simpósio Nacional de Geografia Urbana. Rio Claro. 1991.

CARLOS, A.F.A. A (re)produção do espaço urbano. São Paulo, Editora da Universidade de São Paulo.1994.

CARLOS, A.F.A. O lugar no/do mundo. Editora Hucitec. São Paulo.1996.

CARLOS, A.F.A. Espaço - tempo na metrópole. Editora Contexto. São Paulo, 2001.

CARLOS, A.F.A. (org.) Os caminhos da reflexão sobre a cidade e o urbano. Editora da Universidade de São Paulo, São Paulo. 1994.

CARLOS, A.F.A. (org.) Ensaios de Geografia Contemporânea: Milton Santos Obra Revisitada. Editora Hucitec. São Paulo, 1996.

CARLOS, A.F.A. (org.) Novos caminhos da Geografia. Editora Contexto. São Paulo, 1999.

CARLOS, A. A cidade: Novos caminhos da Geografia. Editora Contexto. São Paulo, 1994.

CARLOS, A. O consumo do espaço. In: (org.). Novos caminhos da Geografia. Editora Contexto. São Paulo,1999.

CERTEAU, M. The Practice of Everyday Life, trans. Steven Rendall. University of California Press, Berkeley. 1984.

CERTEAU, M. A Invenção do Cotidiano: Artes de Fazer. Vozes. Petrópolis, 1994.

COOPER, D.R.; SCHINDLER, P.S. Métodos de pesquisa em administração, 7ª ed. Bookman, 640p. Porto Alegre,2003.

COSTA, N.M.C.; COSTA, V.C. Da escola à natureza: uma experiência de Educação Ambiental em área protegida na cidade do Rio de Janeiro. Interagir: pensando a extensão. n. 16, p. 65-69. Rio de Janeiro, 2011.

CRESWELL, J.W. Projeto de Pesquisa. Métodos Qualitativo, Quantitativo e Misto. 3 ed. Artmed. Porto Alegre,2010. 
CRUZ, N.M.; BARBOSA, C., CARVALHO, P.F. Metodologia para Avaliação e Planejamento de Espaços de Lazer em Cidades Médias: 0 caso de Rio Claro - SP. 2005. Disponível em: $<$ http://www.rc.unesp.br/igce/planejamento/gpapt/>

FEIBER, S.D. ÁREAS VERDES URBANAS IMAGEM E USO - O CASO DO PASSEIO PÚBLICO DE CURITIBA-PR. Raega - O Espaço Geográfico em Análise, [S.I.], v. 8. 2004.

FOUCAULT, M. Verdade e Poder. In: Microfísica do Poder. Graal. Rio de Janeiro, 1977.

FOUCAULT, M. Surveiller et punir. Naissance de la prison. Gallimard. Paris, 1975.

GOMES, C.L.; ELIZALDE, R. Produção de conhecimentos sobre o lazer na América Latina: Desafios e perspectivas. In: ISAYAMA, H.F. (Org.). Produção de conhecimento em estudos do lazer: Paradoxos, limites e possibilidades. 1르. ed. Editora UFMG, p. 113-137. Belo Horizonte, 2014.

GOMES, M.A.S.; SOARES, B.R. Vegetação nos centros urbanos: considerações sobre os espaços verdes em cidades médias brasileiras. Estudos Geográficos, 1(1): 19-29. Rio Claro, 2003.

HARVEY, D. A produção capitalista do espaço. AnnaBlume. São Paulo, 2005.

IRVING M.A., CORRÊA F.V., CONTI B.R., BOTELHO E.S., PEIXOTO S. L. Corcovado: reflexões sobre imaginários e impressões dos turistas no Parque Nacional da Tijuca (RJ, Brasil) no contexto de valorização da cidade pela UNESCO. Revista Brasileira de Ecoturismo. v. 5, n. 3. 201).

LAGE, B.H.G., MILONE, P.C. Fundamentos econômicos do turismo. In Turismo: teoria e prática. Atlas. 2000.

LEFÈBVRE, H. A vida cotidiana no mundo moderno. Ática. São Paulo, 1991.

LEFEBVRE, R.C. Transformative social marketing co-creating the social marketing discipline and brand. Journal of Social. Marketing. V. 2 (2), 118129. 2012.

LOCKWOOD, M. Values and Benefits. In: LOCKWOOD, M; WORBOYS, G.L.; KOTHARI, A. (Ed.). Managing Protected Areas: a global guide. Earthscan, p. 101-115. USA, 2006.

MAFRA G.A. Sinalização interpretativa como ferramenta de educação patrimonial em parques urbanos: o caso do Parque da Serra do Curral de Belo Horizonte. Revista Brasileira de Ecoturismo. V. 3, n. 2, 2010.

MALHOTRA, N. K. Pesquisa de marketing: uma orientação aplicada. $6^{\mathrm{a}} \mathrm{Ed}$. Bookman. Porto Alegre, 2012.

MALTA R. R., COSTA N. M. C. Gestão do Uso Público em Unidade de Conservação: a visitação no Parque Nacional da Tijuca - RJ. Revista Brasileira de Ecoturismo. V. 2, n. 3, 2009. 
MARCELLINO, C. Laser \& Esport: Políticas públicas. Autores Associados. Campinas, 2002.

COSTA, M.C., D'ARROCHELLA, M. L. G., SOUZA, M.A., COSTA, S. S, SAFADI, T. M. O (des) uso público em unidades de conservação: avaliação em algumas áreas protegidas do estado do rio de janeiro. Revista Brasileira de Ecoturismo. v. 4, n. 4, 2011.

MELAZO, G.C.; COLASANTIL, M.T.M. Parques Urbanos: importantes espaços verdes na dinâmica ambiental das cidades. In: Simpósio Regional de Geografia: perspectivas para o cerrado no século XXI, Uberlândia, 2003. Anais... Uberlândia: Universidade Federal de Uberlândia, p.1-15. 2003.

MELO, M.I.O.; DIAS. K.S. Parques urbanos, a natureza na cidade: práticas de lazer e de turismo aliadas à cidadania. Revista Brasileira de Ecoturismo. v. 6, n. 5, 2013.

MENEZES, P.C.; MENDES, L.O.T. The mission of protected areas in Brazil. In: Cities and protected areas (Protected Areas Program). IUCN, v.11, n.3, p.52. Switzerland, 2001.

MOSCARDO, G. Tourism and quality of life: Towards a more critical approach. Tourism and Hospitality Research, 9(2), 159-170, 2009.

NAWIJN, J., VEENHOVEN, R. The effect of leisure activities on life satisfaction: The importance of holiday trips. In BRDAR, I. (Ed.), The human pursuit of well-being: A cultural approach. p. 39-53. Dordrecht, Netherlands, 2011.

OSTRON, ROSENBAUM, et.al. Conceptualization and Aspirations of Transformative Service Research. Journal of Research for Consumers, 19, 1-6. 2015.

PELLIN A., CARVALHO G.; REIS J. Gestão do uso público em parques urbanos: o caso do Parque Estadual da Pedra Branca (RJ), Revista Brasileira de Ecoturismo. v. 7, n. 2, 2014.

PITT, B.; BOULLE, T. Growing together: thinking and practice of urban nature conservators, SANBI Cape Flats Nature, p.156. Cape Town, 2010.

RUST, R.; HUANG, M. The Handbook of Service Marketing Research, Edward Elgar, Northampton, MA, USA, 2014.

SANTOS, M. Pensando o espaço do homem. Hucitec. São Paulo, 1982.

SANTOS, M. A urbanização brasileira. 4. ed. Hucitec. São Paulo, 1998.

SANTOS, M. A natureza do espaço - espaço e tempo: razão e emoção. Hucitec. São Paulo, 1999.

SANTOS, M. A natureza do espaço. São Paulo, EDUSP, 2012.

SERPA, A. O Espaço Público na Cidade Contemporânea. Editora Contexto. São Paulo, 2007.

SOUZA, P.C.A. Funções sociais e ambientais de parque urbano instituído como Unidade de Conservação: percepção dos usuários do Parque Natural Municipal do Barigui, Curitiba, Paraná. Dissertação. Centro de Ciências 
Exatas e de Tecnologia - Pontifícia Universidade Católica do Paraná. Curitiba. 2010.

STREGLIO, C.F.C.; OLIVEIRA, I.J. Parques urbanos de Goiânia-GO: papel social e potencial turístico Goiânia-GO. Raega - O Espaço Geográfico em Análise. v. 23, p. 317-339. 2011.

TOLEDO, F.S; SANTOS, D.G. Espaços Livres de Construção. Revista da Sociedade Brasileira de Arborização Urbana, v.3, n.1, p. 73-91 Piracicaba/ SP, 2008.

TUAN, Y. Topofilia: um estudo da percepção, atitudes e valores do meio ambiente. Trad. Lívia de oliveira. Difel. São Paulo,1980.

TUAN, Y. Espaço e Lugar: a perspectiva da experiência. Trad. Lívia de Oliveira. Difel. São Paulo, 1993.

WARF, B. Humanistic Geography. In: WARF, B. (ed.). Encyclopedia of Human Geography. SAGE Publications. London, 2006.

WEINSTEIN, A. Segmentação de Mercado. Atlas, São Paulo, 1995.

Agradecimento: Este trabalho faz parte projeto de tese desenvolvido no CEPEAD-UFMG, NEECIM-TUR - Núcleo de Estudos e Estratégias de Comunicação Integrada de Marketing.

Ítalo Brener Carvalho: Instituto Federal de Educação Tecnológica de Minas Gerais, Belo Horizonte, MG, Brasil.

E-mail: italobrener@hotmail.com

Link para o currículo Lattes: http://lattes.cnpq.br/7618945227851788

Marlusa de Sevilha Gosling: Universidade Federal de Minas Gerais, Belo Horizonte, MG, Brasil.

E-mail: mg.ufmg@gmail.com

Link para o currículo Lattes: http://lattes.cnpq.br/9503365193492380

Data de submissão: 17 de novembro de 2017

Data de recebimento de correções: 03 de dezembro de 2018

Data do aceite: 03 de dezembro de 2018

Avaliado anonimamente 


\section{Anexo 1: Roteiro de entrevista.}

1. Hoje é sua primeira visita a este parque? Vem aqui com que frequência? Há quanto tempo frequenta este parque?

2. Em sua opinião por que as pessoas visitam este parque? O que elas buscam encontrar aqui?

3. O que você sente quando está aqui? Você sente a mesma coisa em outros lugares?

4. Por que algumas pessoas não frequentam este parque?

5. Estamos interessados em saber se as pessoas que vistam este parque aprendem alguma coisa? O que?

6. Um parque como este contribui pra mudar em que nas pessoas que visitam um parque? O que ele representa?

7. Você levaria visitantes de outas cidades especialmente neste parque? Porque? O que ele representa?

8. O que você acha que os gestores do parque podem fazer para melhorar as experiências dos visitantes em relação ao que o parque oferece? 